\title{
The climatology, propagation and excitation of ultra-fast Kelvin waves as observed by meteor radar, Aura MLS, TRMM and in the Kyushu-GCM
}

\author{
R. N. Davis ${ }^{1}$, Y.-W. Chen ${ }^{2}$, S. Miyahara ${ }^{2}$, and N. J. Mitchell ${ }^{1}$ \\ ${ }^{1}$ Centre for Space, Atmospheric and Oceanic Science, Department of Electronic and Electrical Engineering, \\ The University of Bath, BA2 7AY, UK \\ ${ }^{2}$ Department of Earth and Planetary Sciences, Kyushu University, Fukuoka 812-8581, Japan
}

Correspondence to: R. N. Davis (r.n.davis@bath.ac.uk)

Received: 30 August 2011 - Published in Atmos. Chem. Phys. Discuss.: 31 October 2011

Revised: 16 January 2012 - Accepted: 30 January 2012 - Published: 17 February 2012

\begin{abstract}
Wind measurements from a meteor radar on Ascension Island $\left(8^{\circ} \mathrm{S}, 14^{\circ} \mathrm{W}\right)$ and simultaneous temperature measurements from the Aura MLS instrument are used to characterise ultra-fast Kelvin waves (UFKW) of zonal wavenumber 1 (E1) in the mesosphere and lower thermosphere (MLT) in the years 2005-2010. These observations are compared with some predictions of the Kyushu-general circulation model. Good agreement is found between observations of the UFKW in the winds and temperatures, and also with the properties of the waves in the Kyushu-GCM. UFKW are found at periods between 2.5-4.5 days with amplitudes of up to $40 \mathrm{~m} \mathrm{~s}^{-1}$ in the zonal winds and $6 \mathrm{~K}$ in the temperatures. The average vertical wavelength is found to be $44 \mathrm{~km}$. Amplitudes vary with latitude in a Gaussian manner with the maxima centred over the equator. Dissipation of the waves results in monthly-mean eastward accelerations of $0.2-0.9 \mathrm{~m} \mathrm{~s}^{-1}$ day $^{-1}$ at heights around $95 \mathrm{~km}$, with 5-day mean peak values of $4 \mathrm{~m} \mathrm{~s}^{-1} \mathrm{day}^{-1}$. Largest wave amplitudes and variances are observed over Indonesia and central Africa and may be a result of very strong moist convective heating over those regions. Rainfall data from TRMM are used as a proxy for latent-heat release in an investigation of the excitation of these waves. No strong correlation is found between the occurrence of large-amplitude mesospheric UFKW events and either the magnitude of the equatorial rainfall or the amplitudes of E1 signatures in the rainfall time series, indicating that either other sources or the propagation environment are more important in determining the amplitude of UFKW in the MLT. A strong semiannual variation in wave amplitudes is observed. Intraseasonal oscillations (ISOs) with periods 25-60 days are evident in the
\end{abstract}

zonal background winds, zonal-mean temperature, UFKW amplitudes, UFKW accelerations and the rainfall rate. This suggests that UFKW play a role in carrying the signature of tropospheric ISOs to the MLT region.

\section{Introduction}

Kelvin Waves are equatorially-trapped planetary waves that travel eastwards with respect to the background winds. They propagate upwards away from their sources in the troposphere where they are thought to be excited by the latent heat release associated with tropospheric convection (Holton, 1973; Salby and Garcia, 1987). A classical Kelvin wave has no meridional velocity component and has a latitudinal profile of amplitude that is Gaussian in shape and which maximises over the equator. Amplitudes thus decay with increasing latitude away from the equator (Holton, 1979). The waves can be detected as perturbations in atmospheric wind, temperature and pressure.

Kelvin waves occupy three distinct period ranges. The "slow" Kelvin waves have periods in the range 15-20 days and vertical wavelengths of around $10 \mathrm{~km}$. They were first observed in the lower stratosphere in tropical radiosonde measurements by Wallace and Kousky (1968). They are unable to propagate to greater heights due to selective absorption. The "fast" Kelvin waves were first observed by Hirota (1978) in rocketsonde data. They have periods in the range 6-10 days and vertical wavelengths of around $20 \mathrm{~km}$. The "Ultra-Fast Kelvin Waves", hereafter referred to as UFKW, were first observed by Salby et al. (1984) in 
Nimbus-7 LIMS data. They are usually reported as having periods of around 3.5 days, vertical wavelengths of approximately $40 \mathrm{~km}$ and being an eastward-propagating oscillation of zonal wavenumber 1 (i.e. an E1 wave).

Early work suggested that Kelvin waves might provide the major source of eastward momentum required to drive the Quasi-Biannual Oscillation (QBO) (e.g. Wallace and Kousky, 1968; Holton and Lindzen, 1972) and the Stratospheric Semiannual Oscillation (SSAO) (Dunkerton, 1979). However, later satellite studies (e.g. Hitchman and Leovy, 1988) demonstrated that mesoscale gravity waves provide a necessary additional contribution to the eastward accelerations of the SSAO and model studies came to a similar conclusion for the QBO (e.g. Takahashi and Boville, 1992; Dunkerton, 1997). Nevertheless, studies suggest that Kelvin waves make a significant contribution to the driving of the stratospheric QBO (Kawatani et al., 2010) and UFKW contribute to the eastward momentum of winds in the equatorial lower thermosphere (e.g. Lieberman and Riggin, 1997; Forbes, 2000).

UFKW can reach large amplitudes in the mesosphere and lower thermosphere (MLT) where they can be a significant part of the motion field. UFKW in the MLT have been investigated in a limited number of studies using meteor and MF radars (e.g. Riggin et al., 1997; Kovalam et al., 1999; Sridharan et al., 2002; Pancheva et al., 2004; Younger and Mitchell, 2006; Lima et al., 2008), satellites (e.g. Canziani et al., 1994; Lieberman and Riggin, 1997; Forbes et al., 2009), and models (e.g. Forbes, 2000; Miyoshi and Fujiwara, 2006).

UFKW have been suggested to play a key role in driving the Intraseasonal Oscillations (ISOs) that are observed in the MLT zonal mean temperatures and winds at low latitudes. ISOs with peaks at periods of $\sim 60$ days, $35-40$ days and 22-25 days were first observed in the MLT region by Eckermann and Vincent (1994) in winds obtained from an MF radar on Christmas Island. Eckermann et al. (1997) found similar periodicities in MLT gravity-wave variances and diurnal-tidal amplitudes. They suggested that the 30-60 day Madden-Julian oscillation manifested in the tropical tropospheric convection (Madden and Julian, 1971, 1994) and a separate 20-25 day oscillation over the western Pacific (Hartmann et al., 1992) modulate the gravity-wave and diurnaltidal intensities. These modulated waves and tides then propagate upwards to the MLT and create similar periodicities in the wave-induced driving of the zonal mean flow in the MLT region. The suggestion that the ISO in the MLT zonal winds is wave-driven was supported by Lieberman (1998) using observations of winds from HRDI. Rao et al. (2009) considered radar observations of the MLT made at different longitudes and found that ISO amplitudes vary with longitude, suggesting a close connection to the vigour of convective activity in the underlying troposphere. Intraseasonal variability of UFKW temperature amplitudes with periodicities between 20-60 days was observed in SABER data by Forbes et al. (2009). Modelling results from the extended Kyushu-GCM suggested that Eliassen-Palm Flux Divergences from dissipating UFKW are also important in the wave-mean flow interaction driving the ISO in the MLT region (Miyoshi and Fujiwara, 2006).

The high phase speeds of UFKW, approximately $150 \mathrm{~m} \mathrm{~s}^{-1}$, allow them to propagate into the ionospheric Eregion. It has been suggested that UFKW at these heights may be important in the dynamo generation of electric fields and metallic-ion layering of the E-region, with subsequent modulation effects in the F-region (Forbes, 2000). Large UFKW amplitudes have been observed at heights of 100$120 \mathrm{~km}$ in TIMED/SABER temperature data (Forbes et al., 2009) and at similar heights in the Global-Scale Wave Model (Forbes, 2000). Takahashi et al. (2007) observed a 3-4 day modulation of the day-to-day variability of the ionospheric minimum virtual height $\left(h^{\prime} F\right)$ and of the $F 2$ maximum critical frequency $(f o F 2)$ that may have been associated with simultaneous UFKW activity in the mesosphere. Chang et al. (2010) found in the TIME-GCM that UFKW with realistic MLT amplitudes could cause perturbations in the neutral density at heights of $350 \mathrm{~km}$ and in the total electron content around the equatorial ionisation anomalies via modulation of the dynamo electric field. These observations suggest that UFKW can play an important role in the coupling of different layers of the atmosphere.

Here we use mesospheric winds measured by an equatorial meteor radar and temperatures measured by the Aura microwave limb sounder to investigate UFKW. In particular, we define a representative climatology of the waves, consider their interactions with the mean flow, consider the role of tropospheric latent heat release in their excitation and compare our observations with the predictions of the Kyushu-GCM.

\section{Data and analysis}

The temperature data used in this investigation come from the level 2 version 2.2 temperature product of the Microwave Limb Sounder instrument onboard NASA's Aura satellite. Aura is in a near-polar, sun-synchronous orbit. Temperature values are measured every $25 \mathrm{~s}$ for 34 pressure surfaces between 316 and $10^{-3} \mathrm{hPa}$, corresponding to 34 different height gates. For this study we used the highest gates, centred at heights of approximately 96.7, 91.3, 86.0, 80.6, 75.2, 69.8, $64.4,61.8,59.1,56.4,53.7$ and $51.0 \mathrm{~km}$. There are some small but not significant gaps in the data. The vertical resolution in the mesosphere is approximately $12 \mathrm{~km}$, with temperature precisions of $\sim 2.5 \mathrm{~K}$ (Schwartz et al., 2008). The pressure levels have been converted into geometric heights to allow direct comparison with the radar observations. The data considered here covered the interval 1 January 2005 to 31 December 2010.

The wind data are from the Ascension Island SKiYMET meteor radar, located at $8^{\circ} \mathrm{S}, 14^{\circ} \mathrm{W}$. Winds are obtained as hourly averages within six height gates centred at 80.5, 84.5, 
a) ZONAL
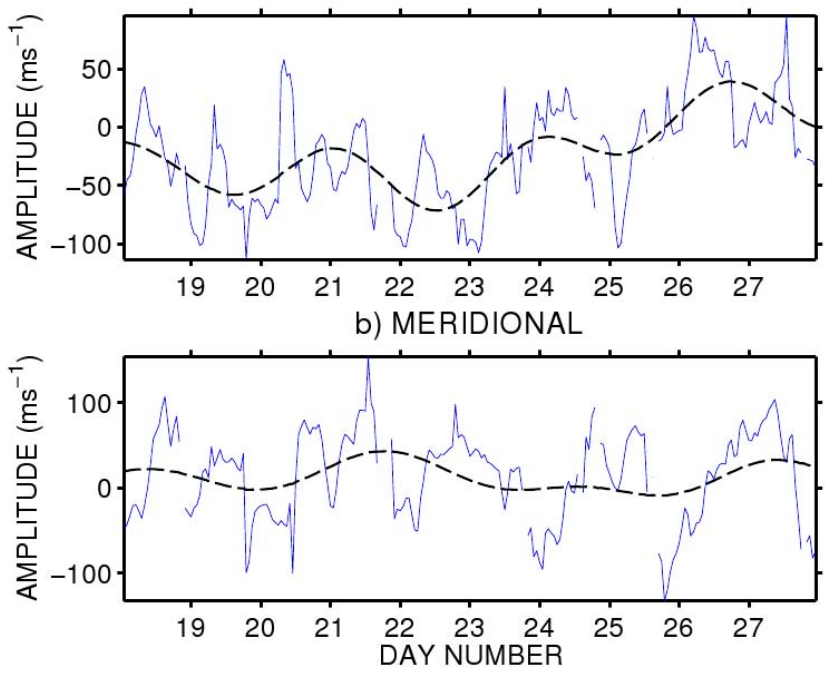

Fig. 1. Raw hourly (a) zonal and (b) meridional winds at a height of $96 \mathrm{~km}$ from the Ascension Island radar with low-pass filtered winds overlaid (dashed line) for the period 18-28 January 2005. The cutoff of the filter is 2.5 days. Note the oscillations in the zonal winds with period near 3 days.

87.5, $90.5,93.5$ and $97.0 \mathrm{~km}$. The radar began operating in May 2001, but for this study we have considered only the data overlapping the complete years available from Aura MLS, i.e. from 1 January 2005 to 31 December 2010. There are some significant gaps in the radar dataset amounting to $22 \%$ of $2005,17 \%$ of $2006,71 \%$ of $2007,100 \%$ of 2008 , $58 \%$ of 2009 and $27 \%$ of 2010 .

Tropospheric convective heating may play a role in UFKW excitation. Here we have used precipitation data from the TRMM "Multi-satellite Precipitation Analysis" dataset as a proxy for the latent heat release associated with tropospheric convection.

Finally, our observations are compared to the predictions of the Kyushu-GCM T42L250 version. This model uses triangular-truncation at wavenumber 42 in the horizontal and 250 layers in the vertical. The model covers heights from the ground up to approximately $150 \mathrm{~km}$. In the MLT region the vertical resolution is $\sim 500 \mathrm{~m}$. The GCM includes shortand long-wave radiation processes, moist and dry convective adjustments, a local Richardson number dependent vertical eddy diffusion process and various other physical processes. Monthly-mean sea surface temperatures are used as a lower boundary condition. The ground temperature is calculated in the model by using its heat balance. No gravity-wave parameterization is used, but a Rayleigh friction is imposed on the zonal-mean zonal winds to weaken the zonal winds around the mesopause. More details can be found in Chen and Miyahara (2011).
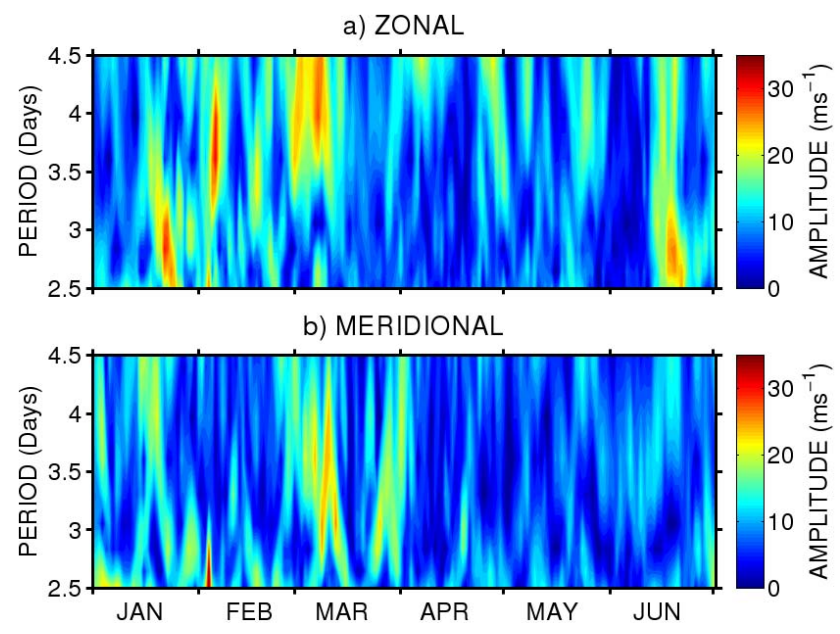

Fig. 2. Running Lomb-Scargle periodogram of (a) zonal and (b) meridional winds over Ascension Island for January-June 2005 at a height of $96 \mathrm{~km}$.

\section{Results}

\subsection{Ascension Island meteor radar observations}

Zonal winds measured over Ascension Island frequently show wave-like oscillations with periods near 3-4 days. As an example, Fig. 1 presents hourly-mean zonal and meridional winds for a height of $96 \mathrm{~km}$ for the interval 18-28 January 2005.

The figure shows a motion field dominated by a largeamplitude oscillation of period $24 \mathrm{~h}$, which is the diurnal tide. Also present are lower-frequency oscillations. The dashed lines on the figure show the hourly winds low-pass filtered to reveal oscillations with periods longer than 2.5 days. The filtered winds reveal oscillations of period 3-4 days with amplitudes reaching up to $30 \mathrm{~m} \mathrm{~s}^{-1}$ in the zonal component and $20 \mathrm{~m} \mathrm{~s}^{-1}$ in the meridional component. The fact that the period of oscillation is about 3-4 days, combined with the larger amplitudes in the zonal component, is a strong indication that these winds are the signature of ultra-fast Kelvin waves (note that there is also an indication of the 2-day wave in the meridional unfiltered winds).

To further investigate the possible presence of UFKW, a dynamic spectrum of zonal and meridional winds was calculated for all six radar height gates and for all years of the meteor-radar data. Figure 2 presents an example of these results for January-June 2005 for a height of $96 \mathrm{~km}$. The spectra were calculated using a Lomb-Scargle periodogram applied to a data window of ten days, incremented through the dataset in steps of 1 day.

Considering the figure in detail it can be seen that events with period 3-4 days occur in an episodic manner and are particularly noticeable in January-March 2005. Zonal wind amplitudes regularly exceed $15 \mathrm{~m} \mathrm{~s}^{-1}$ and sometimes exceed 


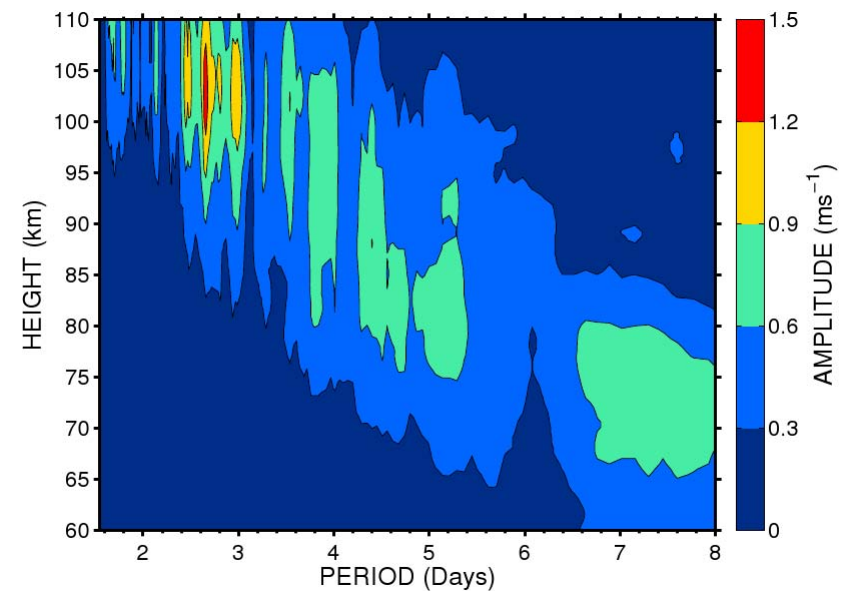

Fig. 3. Annually-averaged amplitude as a function of wave period vs. height of E1 waves in the zonal wind at $2.1^{\circ} \mathrm{N}$ in the KyushuGCM.

$30 \mathrm{~m} \mathrm{~s}^{-1}$ in the wave-period band $2.5-4.5$ days associated with UFKW. When we consider the full dataset, we find peak amplitudes of up to $40 \mathrm{~m} \mathrm{~s}^{-1}$. Wave amplitudes and periods vary greatly on timescales of a few days, demonstrating strong intermittency. However, there is also a suggestion of longer-term variability because wave amplitudes in January, February and March appear significantly larger than in April. These features of intermittency and stronger January-March activity (and weaker April-June activity) are typical of all years, however we will consider seasonal variability later. Meridional amplitudes can be large but are generally smaller than the zonal amplitudes. For example, the largest zonal amplitudes in January and February are $>30 \mathrm{~m} \mathrm{~s}^{-1}$ while the largest meridional amplitudes are about $15 \mathrm{~m} \mathrm{~s}^{-1}$. This observation, combined with the observed wave periods, provides a strong indication that these spectral signatures result from UFKW. Further, note that the theoretical suggestion that UFKW have zero meridional velocities is actually based on a simplified set of assumptions and so UFKW observed away from the equator may have non-zero meridional components.

The period range of UFKW in the MLT region can also be investigated in the Kyushu-GCM. The composite-year period-height distribution of E1 wave amplitudes in the model is presented in Fig. 3. The figure shows that at heights around $95 \mathrm{~km}$ Kelvin waves have a period range of approximately 2-6 days with largest amplitudes between 2.5-4.5 days. The GCM amplitudes seem low when compared to observations but this is because they represent an annualaverage, which due to the intermittency of the waves will include intervals of little to no UFKW activity, which supresses the average amplitudes.

We will hereafter interpret the 2.5-4.5 day oscillations seen in the zonal spectra of Fig. 2 as being due to UFKW (further justification for this assumption is provided by the simultaneous observation of eastward-propagating oscillations

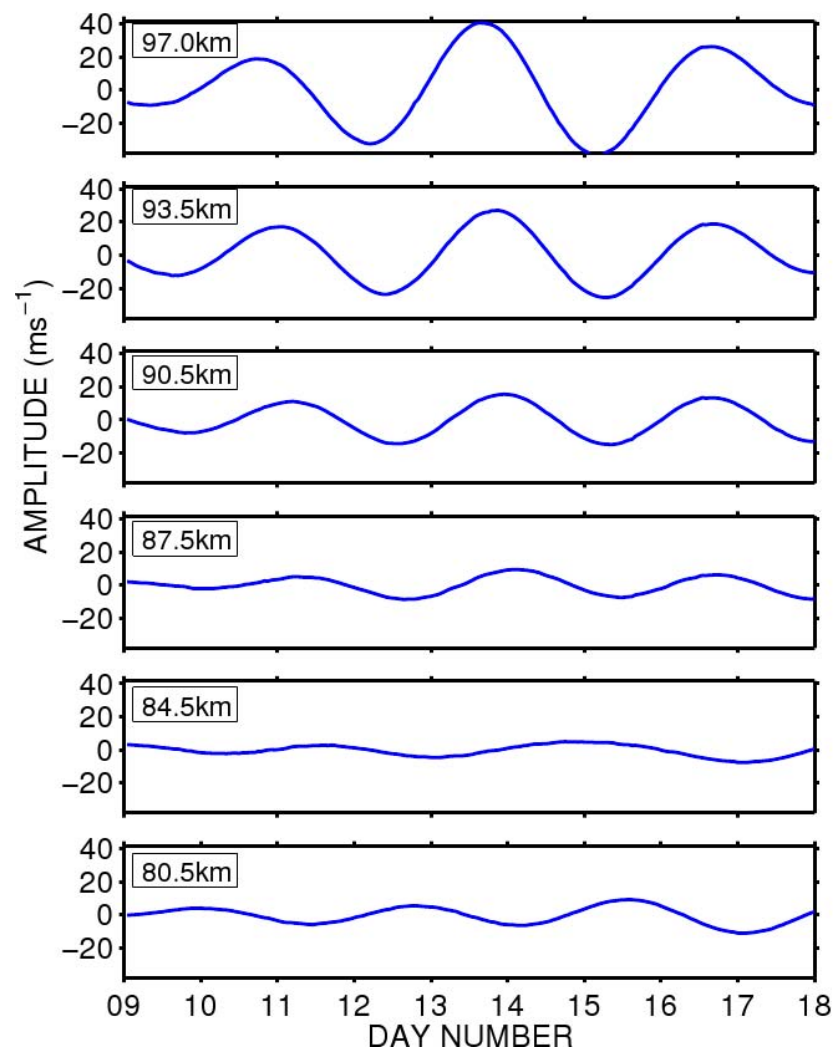

Fig. 4. Zonal winds over Ascension Island for the period 9-18 January 2006 bandpassed between $2.5-4.5$ days for six heights (height labels represent the centre of each gate).

of zonal wavenumber 1 in the Aura analysis of Sect. 3.2). However, note that the inertial period at Ascension island is $86 \mathrm{~h}$ and so low-frequency inertia-gravity waves may also make some contribution to the motion field.

We observe that the UFKW amplitudes vary strongly with height and show a marked tendency to have greater amplitudes at greater heights. As an example, Fig. 4 presents the band-passed (2.5-4.5 days) zonal winds for 9-18 January 2006. Wave amplitudes can be seen to increase from about $5 \mathrm{~m} \mathrm{~s}^{-1}$ at $80.5 \mathrm{~km}$ to $40 \mathrm{~m} \mathrm{~s}^{-1}$ at $97 \mathrm{~km}$.

To investigate the seasonal variability of the UFKW observed by the radar we calculated monthly variances of zonal winds in each height gate for each year for the period range 2.5-4.5 days representative of UFKW. A climatology was constructed using a composite-year analysis of all of the monthly variances from all the available data between 2005 and 2010. The results of this analysis are presented in Fig. 5a, which shows that the variances reach the largest values in July-August and have minima near the equinoxes in March-May and October. Secondary maxima are evident in January-February and November.

In all months wave variance increases with height. This is particularly striking in August where the variance increases from about $70 \mathrm{~m}^{2} \mathrm{~s}^{-2}$ near heights of $80 \mathrm{~km}$ to more 


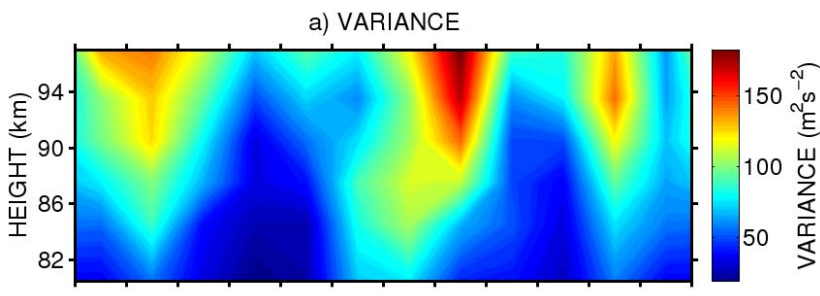

b) ST. DEV. OF VARIANCE

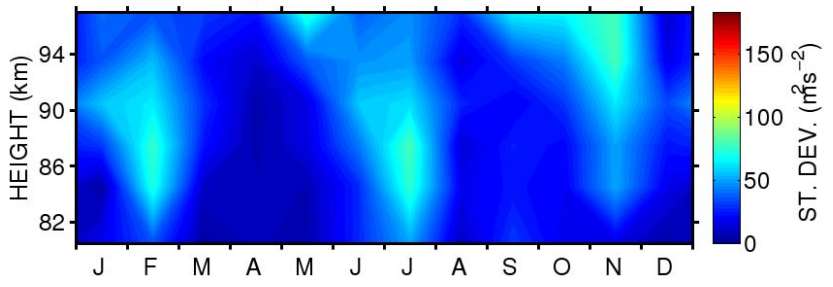

Fig. 5. (a) Monthly variance as a function of height for a composite year of all available data between 2005 and 2010 of zonal winds over Ascension Island. The winds are bandpassed between periods of 2.5-4.5 days. (b) The standard deviation of the monthly variance values for each height gate and each month.

than $170 \mathrm{~m}^{2} \mathrm{~s}^{-2}$ near heights of $97 \mathrm{~km}$. The seasonal pattern of variances is generally similar for all years observed. Some year-to-year variability is, however, evident. Figure 5b presents contours of the standard deviation of the variance values for each height gate and each month as a measure of this variability. The mean standard deviation averaged over all heights and months was $35 \mathrm{~m}^{2} \mathrm{~s}^{-2}$.

\subsection{Aura MLS observations}

The UFKW also cause fluctuations in atmospheric temperature which can be measured with Aura MLS.

UFKW can be seen in the unfiltered MLS data when the temperatures are plotted against longitude and time in a Hovmöller diagram. This representation has the advantage of showing any longitudinal variations of the UFKW, rather than the zonal-mean structure. As an example, Fig. 6 presents a Hovmöller diagram of wave-induced temperature perturbations as a function of time and longitude for the period 17 July-15 August 2005 for a height of $97 \mathrm{~km}$. The temperature fluctuations are measured within a $10^{\circ}$ latitudinal band centred over the equator, divided into 12 longitudinal sectors, each of $30^{\circ}$ longitudinal extent. A time window of one day is used, stepped through the dataset in increments of $12 \mathrm{~h}$ and the daily longitudinal average is subtracted from each segment. No filtering in time is used.

A quasi-monochromatic wave-like pattern is clearly evident, dominating the figure. This corresponds to an eastward propagating wavenumber 1 wave of period $\sim 3.6$ days. These properties are characteristic of UFKW and suggest that such waves might be easily identified in the MLS data. Peak amplitudes reach up to $\sim 15 \mathrm{~K}$ and are $\sim 6 \mathrm{~K}$ over much of the

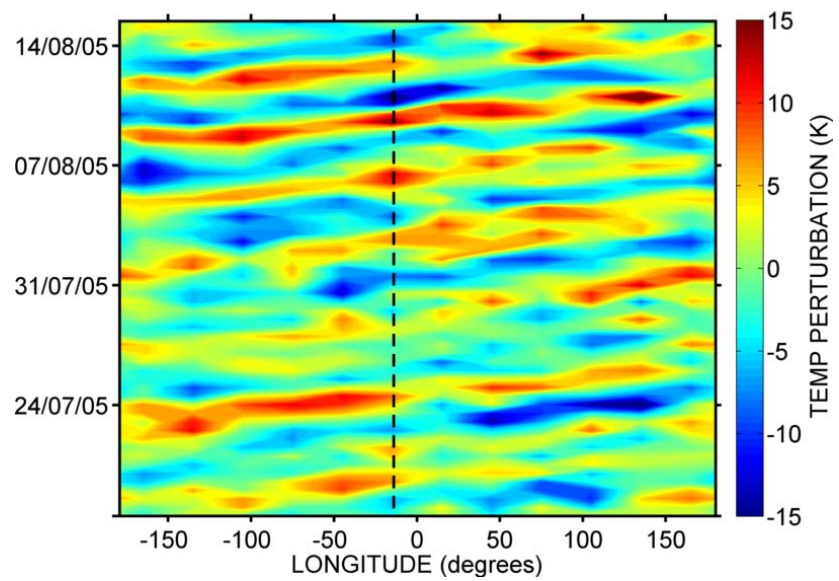

Fig. 6. Hovmöller diagram of Aura MLS temperatures with daily longitudinal means subtracted for 17 July to 15 August 2005 at a height of $97 \mathrm{~km}$. The dashed line represents the longitude of Ascension Island.

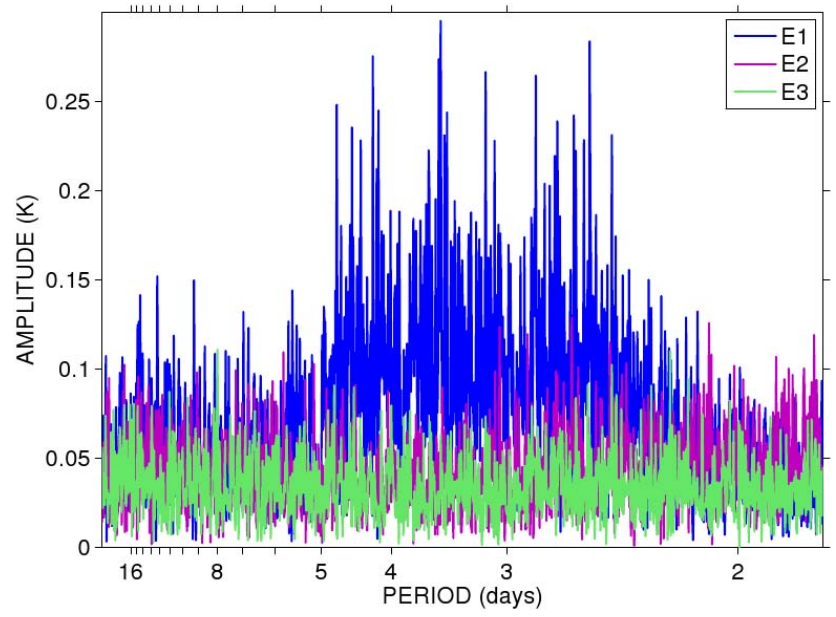

Fig. 7. Spectra showing amplitudes for E1, E2 and E3 wavenumbers resulting from a 2D-FFT of the temperature perturbations as a function of time and longitude. For the 2D-FFT the entire 2005-2010 interval was used. The data are for a height of $97 \mathrm{~km}$ and within a $10^{\circ}$ latitudinal band centred over the equator.

figure. It can also be seen that the amplitude of the wave shows some longitudinal variability.

To investigate the presence of UFKW at different wavenumbers in the Aura MLS dataset, a 2D-FFT was taken of temperature perturbations as a function of longitude and time for the whole of the 2005-2010 interval (an example of these temperature perturbations were presented in Fig. 6). The 2D-FFT identifies the dominant frequencies (from the time domain) and wavenumbers (from the longitudinal domain). The result is presented in Fig. 7, which has been limited to showing the E1, E2 and E3 wavenumbers for reasons of clarity. 
It can be seen in the figure that there are peaks of large amplitude occurring between wave periods of 2.5 and 4.5 days in the E1 component, i.e. periods associated with UFKW. Within this period band only small amplitudes are evident in the E2 and E3 components. We thus restrict the scope of this paper to the E1 components of the waves.

The zonal-mean structure of the UFKW in the Aura data was investigated using the least-squares planetary-wave analysis method of Wu et al. (1995), which determines a zonal-mean amplitude for a specified wave period and zonal wavenumber. The spectral composition of the E1 wave field was determined using a dynamic spectrum of the temperature data, in which the amplitude of E1 oscillations was calculated for wave periods stepped through the period range 2.5-4.5 days in increments of $1 \mathrm{~h}$. Fitting windows of length 10 days were used as a compromise between spectral and temporal resolution. This analysis was repeated for the different heights and latitudes of the Aura dataset.

An example of this analysis is presented in Fig. 8a, which shows E1 wave amplitudes as a function of wave period and time at a height of $97 \mathrm{~km}$ at the latitude of Ascension island for the same interval of time as shown in the radar results of Fig. 2 (i.e. January-June 2005). The figure shows short-lived peaks in wave amplitude that often appear to correspond to the UFKW spectral peaks evident in the wind data from Ascension Island shown in Fig. 2. For example, the seven peaks indicated by arrows on the time axis all appear to have corresponding features in the wind spectra of Fig. 2. This provides evidence that the radar and Aura MLS are observing the same UFKW since the Wu et al. analysis reveals only E1 planetary waves.

The majority of the spectral peaks in Fig. 8a have amplitudes maximising at about $3 \mathrm{~K}$ (although note that when the entire 6-yr dataset was examined a small number of peaks were found with amplitudes reaching up to $6 \mathrm{~K}$ ). The largest mean error on the wave amplitudes at equatorial latitudes was found to be about $0.5 \mathrm{~K}$, and so here we will only consider oscillations with amplitudes larger than $0.5 \mathrm{~K}$. The similarity of the peaks in Fig. 8 to those in the radar spectra (Fig. 2) leads us to conclude that they are the manifestations in MLT temperature of the same UFKW observed by the radar.

To further investigate the agreement between the meteor radar and satellite results, time series of amplitudes were produced for each year 2005 to 2010 for waves with period 3.5 days from both the meteor radar running Lomb-Scargle analysis and from the Aura MLS zonal mean amplitude analysis. Considering only those years with more than eight months of radar data, we calculated correlations between the two time series of amplitudes. This system has 43 degrees of freedom and a correlation of $r=0.44$, significant at the $99 \%$ level, indicating that the meteor radar and MLS are effectively observing the same UFKW wave field.

Figure $8 \mathrm{~b}$ presents E1 wave amplitudes as a function of latitude and time for a height of $97 \mathrm{~km}$ and averaged over the
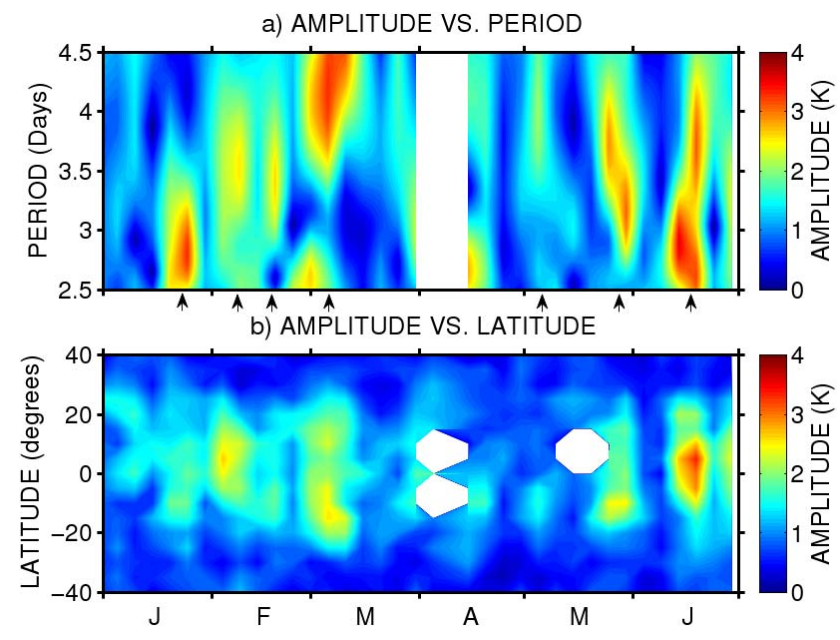

Fig. 8. Amplitude of E1 waves derived from Aura MLS temperature measurements at a height of $97 \mathrm{~km}$ as a function of (a) wave period at the latitude of Ascension Island $\left(8^{\circ} \mathrm{S}\right)$ and (b) latitude. In (b), the amplitudes are averaged over wave periods of 2.5-4.5 days. The data cover the interval January-June 2005. The arrows on (a) indicate the times at which large amplitude UFKW events were observed over Ascension Island in Fig. 2.

wave-period range $2.5-4.5$ days. The figure shows that wave amplitudes maximise at low latitudes near or on the equator.

To investigate the latitudinal structure in more detail the variation of amplitude with latitude was determined for welldefined, large-amplitude events. To do this, an amplitude threshold of $3.5 \mathrm{~K}$ at the equator was set for the highest height gate and 16 events exceeding this threshold were identified in the data, the central date of each is given in Table 1. The mean amplitude as a function of latitude for these 16 events is shown in Fig. 9 for heights from approximately 65 to $97 \mathrm{~km}$. Also plotted on the figure is the amplitude profile for a 3.75 day UFKW at $97 \mathrm{~km}$ height from the Kyushu-GCM, normalised to the largest amplitude in the MLS data.

The figure shows that the UFKW amplitudes have an approximately Gaussian shape centred over the equator with an e-folding half-width (at a height of $97 \mathrm{~km}$ ) of $27^{\circ}$ of latitude. Wave amplitudes for all heights reach a minimum value between $25^{\circ}$ and $40^{\circ}$ latitude in both hemispheres. The shape of the latitudinal profile of amplitude observed in the Aura MLS data is very similar to that of the UFKW produced in the Kyushu-GCM. It is slightly steeper, however this is as expected as the 3.75 day period used to produce the Kyushu line is towards the longer end of the 2.5-4.5 day range that the Aura MLS data were averaged over and longer periods correspond to slower waves and narrower profiles (see Discussion).

The period at which UFKW amplitudes peak as a function of height was investigated in the Aura MLS data by taking the average over all six years of wave amplitudes (derived by the least-squares fit method) for each period and for each 


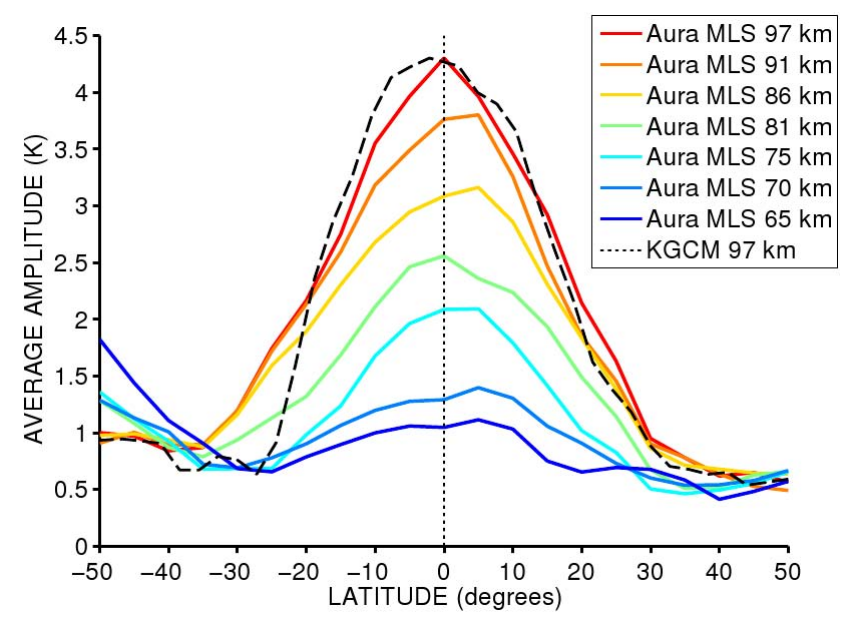

Fig. 9. Average amplitude as a function of latitude for $16 \mathrm{E} 1$ waves identified in Aura MLS data for seven different heights between 65 and $97 \mathrm{~km}$. Only events with a maximum amplitude exceeding $3.5 \mathrm{~K}$ were included. Also plotted is the amplitdue profile for 3.75 day waves at $97 \mathrm{~km}$ height from the Kyushu-GCM (black dashed line), normalised to the largest amplitude in the MLS data.

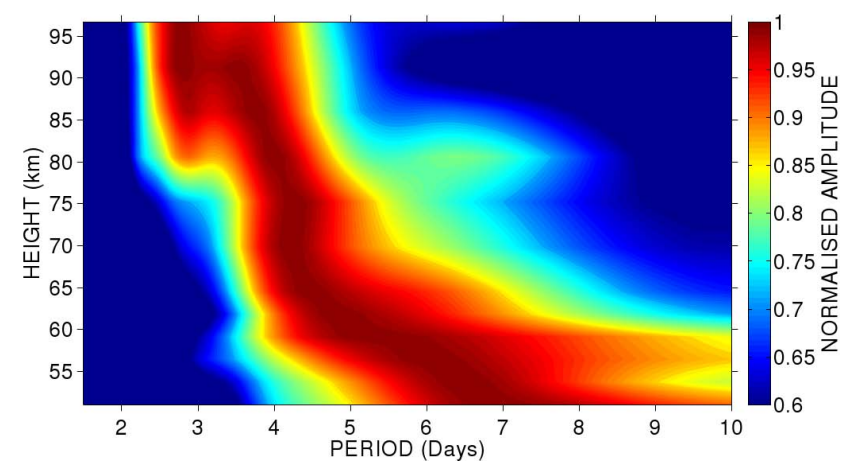

Fig. 10. Normalised wave amplitudes as a function of height for E1 waves in the MLS temperature data averaged over the interval 2005-2010.

satellite height gate. As the amplitude growth with increasing height otherwise dominates the figure, the mean amplitudes were normalised for each height gate to better show how the amplitudes varied with period at lower heights. The result of this analysis is presented in Fig. 10.

The figure shows that at the heights observed by the meteor radar the dominant wave periods are 2.5-4.5 days. The figure also shows a tendency for wave periods to increase at lower heights. This is in good qualitative agreement with the model results of Fig. 3.

The longitudinal variability that can be observed in Fig. 6 was explored by producing a Hovmöller diagram for the entire interval of 2005-2010, with 18 sectors of $20^{\circ}$ longitudinal width and $10^{\circ}$ latitudinal width centred over the equator. Within each sector the time series of temperature perturbations were then bandpassed within period limits of 2.5-4.5

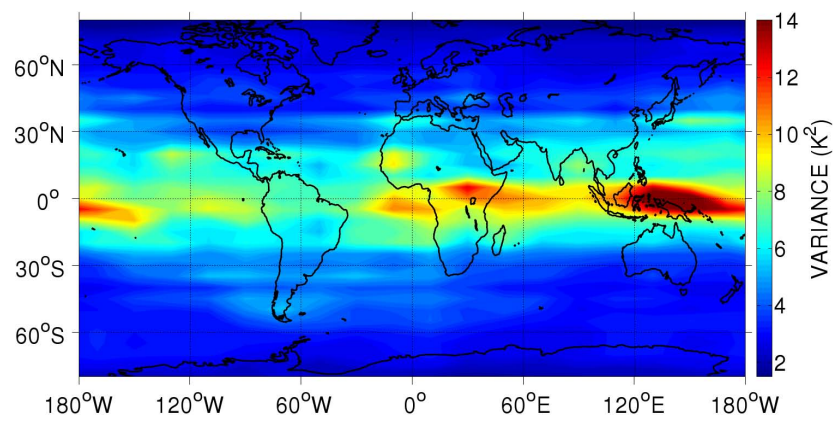

Fig. 11. Variance of temperature perturbations derived from bandpassed temperature time series between periods of 2.5-4.5 days as a function of latitude and longitude from Aura MLS temperatures for 2005-2010 at a height of $97 \mathrm{~km}$. The sectors are of $20^{\circ}$ longitudinal width and $10^{\circ}$ latitudinal width.

days. This was done to reject the contributions from planetary waves at other periods (e.g. the 6-day wave which can reach large amplitudes at low latitudes). The variance was then calculated for each sector. This was repeated for longitudinal belts centred over other latitudes. The results of this analysis are presented in Fig. 11.

The figure shows a longitudinal band of large variance in the 2.5-4.5 day period range that is centred over the equator and diminishes with increasing latitude out to approximately $25^{\circ} \mathrm{N} / \mathrm{S}$. Peaks in variance are evident over Indonesia (longitudes $\sim 120-160^{\circ} \mathrm{E}$ ) and central Africa (longitudes $\sim 15-35^{\circ} \mathrm{E}$ ). These two regions of the equator are known to be areas of strong convective activity in the troposphere. However, large variances are also apparent over the Indian ocean (longitudes $\sim 60-90^{\circ} \mathrm{E}$ ) and central Pacific (longitudes $\sim 180-150^{\circ} \mathrm{W}$ ). Interestingly, the smallest variances are observed near longitudes of $60^{\circ} \mathrm{W}$ over South America, despite the fact that this would also be expected to be a region of strong convective activity. A peak in the wave activity was also observed over Indonesia by Kovalam et al. (1999) and Riggin et al. (1997), and is discussed further in Sect. 4. The longitudinal variability is less striking away from the equator, with variances more uniform around the longitudinal circle. Finally, we should note that the relatively short sampling time of the satellite within each latitude-longitude box may result in a contribution to the temperature variance from unresolved inertia-gravity waves.

As the UFKW propagate upwards, the phase of the waves change with height and so the vertical wavelength can be estimated. The wavelengths were calculated for the 16 largeamplitude wave events described above. The phase as a function of height is plotted for a typical UFKW event as an example in Fig. 12, shifted so that its phase starts at 0 radians in the top height gate. Also plotted is the best fit straight line. In each individual case the wave period was fixed at the period value for which the wave amplitude maximised. The variation of phase against height was then determined for that 


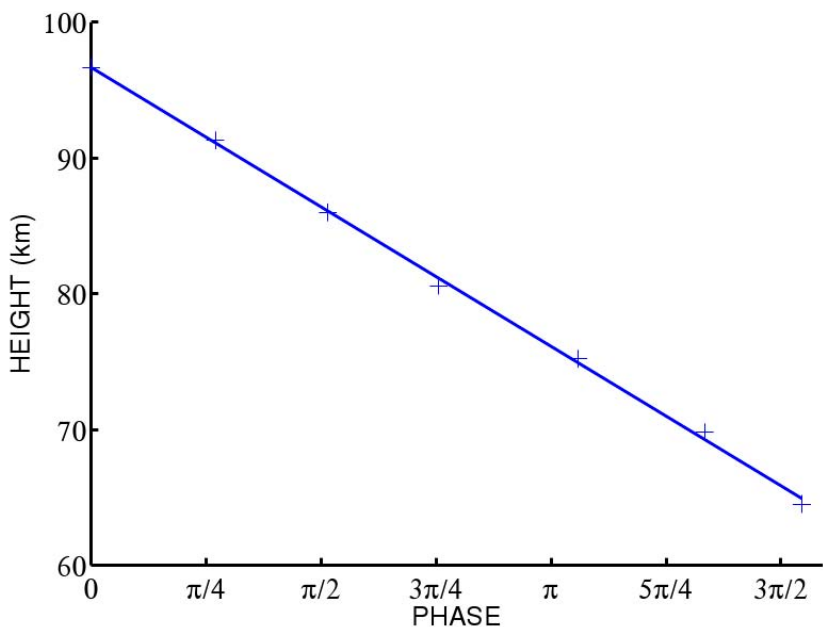

Fig. 12. Phase as a function of height for the single large-amplitude E1 UFKW event observed over a ten-day interval centred on $3 \mathrm{Au}-$ gust 2005, obtained from Aura MLS observations. Phase has been arbitrarily set to zero in the top height gate. The best-fit straight line is indicated and corresponds to a vertical wavelength of $41 \pm 1 \mathrm{~km}$.

Table 1. Vertical wavelengths, $\lambda_{z}$, for 16 large amplitude UFKW events in the Aura MLS data centred on the dates given. The mean vertical wavelength is $44 \pm 2 \mathrm{~km}$.

\begin{tabular}{llll}
\hline Date & $\lambda_{z}(\mathrm{~km})$ & Date & $\lambda_{z}(\mathrm{~km})$ \\
\hline 3 Aug 2005 & $41 \pm 1$ & 24 Feb 2008 & $48 \pm 3$ \\
1 Nov 2005 & 39 \pm 1 & 3 Jul 2008 & $42 \pm 2$ \\
12 Sep 2006 & $52 \pm 2$ & 24 Jan 2009 & $43 \pm 2$ \\
22 Oct 2006 & $41 \pm 3$ & 3 Jun 2009 & $36 \pm 1$ \\
30 Jan 2007 & 49 \pm 1 & 27 Aug 2009 & $43 \pm 2$ \\
24 Jun 2007 & $37 \pm 1$ & 6 Aug 2009 & $48 \pm 3$ \\
4 Jul 2007 & $43 \pm 3$ & 26 Oct 2009 & $46 \pm 2$ \\
3 Aug 2007 & $50 \pm 5$ & 23 Jul 2010 & $41 \pm 1$ \\
\hline
\end{tabular}

period. For example, the period of the event shown in Fig. 12 was found to be $92 \mathrm{~h}$. It can be seen from the figure that the phase changes with height in a very smooth and well-defined manner.

The corresponding vertical wavelengths for the 16 events, obtained from the lines of best fit, are given in Table 1. The vertical wavelengths are all rather similar, ranging from 36$52 \mathrm{~km}$, with an average of $\lambda_{z}=44 \pm 2 \mathrm{~km}$.

The seasonal variability of the E1 UFKW amplitudes in the temperature field was investigated by taking an average of the least-squares fitted amplitudes over the period range 2.54.5 days, for each of the four height gates in the $80-100 \mathrm{~km}$ height range and for each month. The results of this analysis are presented as monthly means in a composite year 20052010 in Fig. 13, which shows a very similar seasonal variability to the corresponding radar result presented in Fig. 5 .

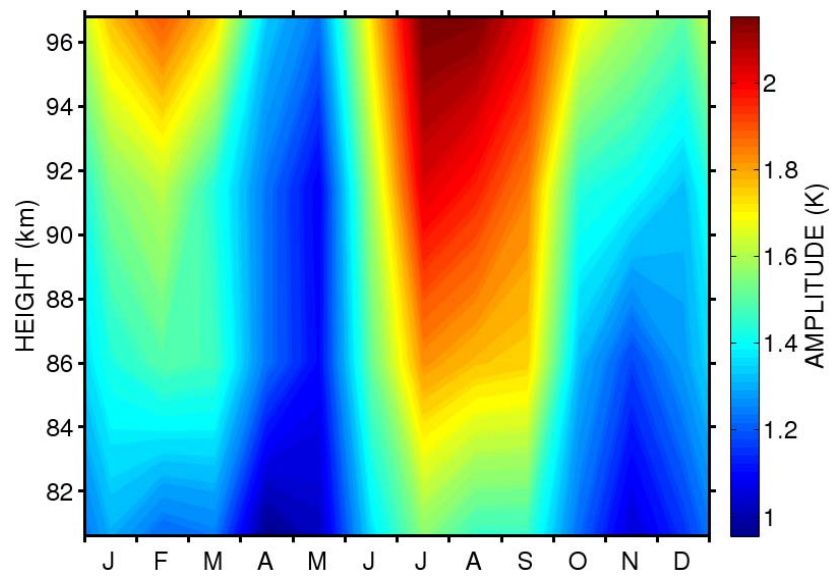

Fig. 13. Aura MLS E1 UFKW monthly-mean amplitudes averaged over the 2.5-4.5 day period band as a function of height for a composite year of the 2005-2010 data.

Average UFKW amplitude is seen to increase with height from between $1.0-1.5 \mathrm{~K}$ at heights near $81 \mathrm{~km}$ to peaks of $\sim 2.2 \mathrm{~K}$ at $97 \mathrm{~km}$. The greatest amplitudes are in the months February and August, as observed in the radar data. The peak of $2.2 \mathrm{~K}$ is smaller than the amplitudes presented in Fig. 9, but this is just a result of averaging many individual events of greater amplitude along with quieter episodes. Individual waves may thus have larger amplitudes than indicated by Fig. 13.

\subsection{Momentum fluxes}

The vertical flux of horizontal momentum, $P$, carried by the UFKW was determined using the method described in Kovalam et al. (1999) and Riggin et al. (1997). The momentum flux is given by $\rho \overline{u^{\prime} w^{\prime}}$. The meteor radar can measure horizontal winds but cannot easily measure vertical winds. However, using the dispersion relation for UFKW allows an estimate of $P$ to be made in terms of atmospheric density, $\rho$, horizontal perturbation winds from the UFKW, $u^{\prime}$, the scale height, $H$, and the horizontal and vertical wavenumbers of the UFKW, $k$ and $m$, respectively. Following Kovalam et al. (1999), $P$ is given by

$P=\frac{1}{2} \rho \overline{u^{\prime 2}} \Re\left[-\frac{k}{\left(m^{2}+\frac{1}{4 H^{2}}\right)}\left(m-\frac{i}{2 H}\right)\right]$

The mesospheric densities for the different height gates and months were obtained from the MSIS-E-90 atmospheric model. The average of the UFKW vertical wavelengths obtained from the Aura MLS analysis was used to determine $m\left(-0.00014 \mathrm{rad} \mathrm{m}^{-1}\right)$. The value for $k$ was obtained by assuming a zonal wavenumber 1 . The results of this analysis are shown in Fig. 14 in terms of monthly momentum fluxes in a composite year calculated using all available radar data between 2005 and 2010. 


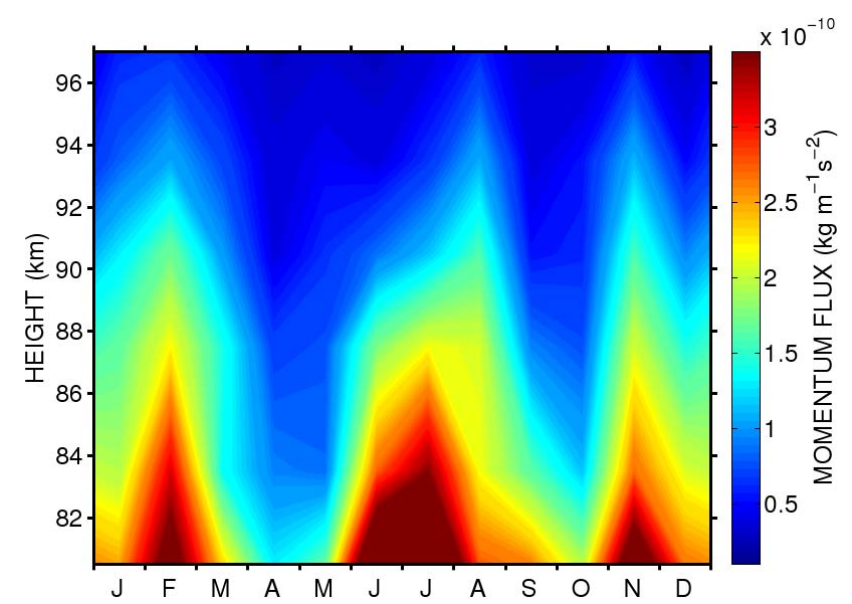

Fig. 14. UFKW Momentum Fluxes for a composite year of data available between 2005-2010 obtained using Ascension Island meteor-radar. Bandpassed winds were used between period limits of 2.5-4.5 days.

From the figure it can be seen that momentum fluxes maximise in February, July and November, with distinct minima between these months. This seasonal variation is very similar to the variation in UFKW variance shown in Fig. 5. However, as height increases, the gas density decreases at a greater rate than the variance increases, resulting in a decrease of momentum flux with height in all months and also explaining the apparent shift of an August variance peak to a July momentum flux peak (at heights near $80 \mathrm{~km}$ where the density is much greater than at $97 \mathrm{~km}$, the variance peaks in July). The momentum fluxes decrease strongly with increasing height from peak values at the lowest heights observed. For instance, momentum fluxes in July have peak values of more than $3.5 \times 10^{-10} \mathrm{~kg} \mathrm{~m}^{-1} \mathrm{~s}^{-2}$ at heights around $80 \mathrm{~km}$, but decrease to around $6 \times 10^{-11} \mathrm{~kg} \mathrm{~m}^{-1} \mathrm{~s}^{-2}$ at heights around $97 \mathrm{~km}$.

The momentum lost from the UFKW is deposited into the mean flow, where it causes an eastward acceleration of the zonal winds. This acceleration can be calculated from the vertical gradient of $P$ (i.e. $\frac{\mathrm{d} P}{\mathrm{~d} z}$ ) and knowledge of $\rho$. Using the MSIS-E-90 values of $\rho$ described above, the zonal acceleration in the mean flow resulting from the UFKW was calculated for each year. The results for the acceleration between the two highest height gates for the year 2006 are shown as an example in Fig. 15.

Considerable variability in the zonal acceleration is evident on the intraseasonal timescales of 25-60 days. Accelerations vary from $-1 \mathrm{~m} \mathrm{~s}^{-1}$ day $^{-1}$ to nearly $4 \mathrm{~m} \mathrm{~s}^{-1}$ day ${ }^{-1}$. The acceleration is generally positive (eastward), and this is true for all years considered. However, we note that there are occasional episodes of modest westwards acceleration. These may be the result of inertia-gravity waves or mixed Rossby-gravity waves present in the range of wave periods considered (note that the gravity wave spectrum will extend

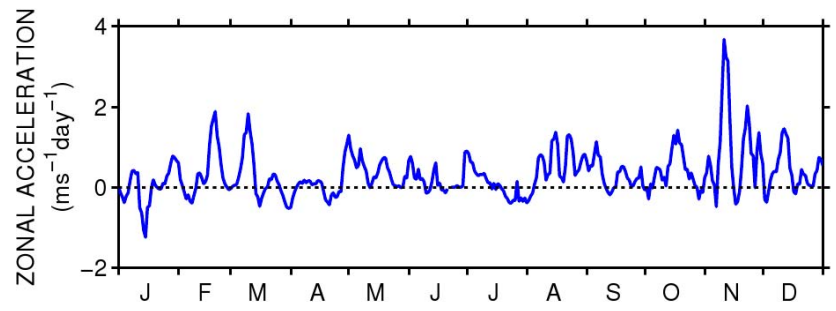

Fig. 15. Zonal acceleration (or body force per unit mass) obtained from UFKW measured by the Ascension Island meteor-radar at heights between 93.5 and $97.0 \mathrm{~km}$ for the year 2006 .

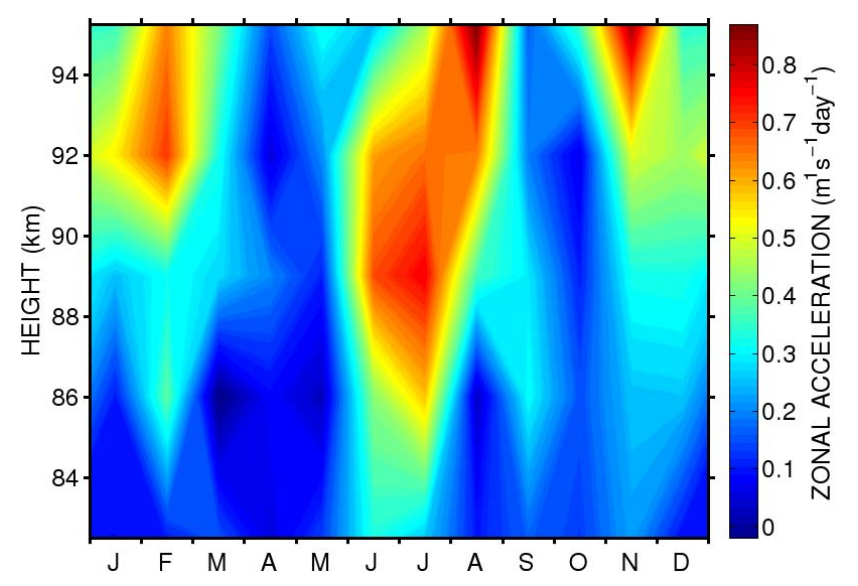

Fig. 16. Zonal Acceleration (or body force per unit mass) resulting from UFKW with periods between $2.5-4.5$ days, measured by the Ascension Island radar for the composite year of data available between 2005-2010.

up to the inertial period of $\sim 86 \mathrm{~h}$ at the latitude of Ascension Island). To investigate the seasonal variability of the zonal acceleration, a composite-year figure was produced by averaging all available monthly-mean acceleration values between each height gate. This composite year analysis is presented in Fig. 16.

Zonal accelerations are seen to have maximum values in February, August and November, and the zonal acceleration generally increases with increasing height, from values of around $0.1 \mathrm{~m} \mathrm{~s}^{-1}$ day $^{-1}$ at lower heights up to peaks of nearly $0.9 \mathrm{~m} \mathrm{~s}^{-1} \mathrm{day}^{-1}$ higher up. This range of accelerations is similar to that observed by Kovalam et al. (1999) and Riggin et al. (1997). These contours of zonal acceleration look quite similar to those of zonal variance (Fig. 5) indicating that zonal acceleration approximately follows UFKW variance.

\subsection{TRMM Observations and the Kyushu-GCM}

A proposed source of UFKW in the MLT is moist convective heating in the equatorial troposphere. To investigate this proposal further, we explored this mechanism in the KyushuGCM and used TRMM rainfall data as a proxy for convective heating to enable comparisons with our observations. 

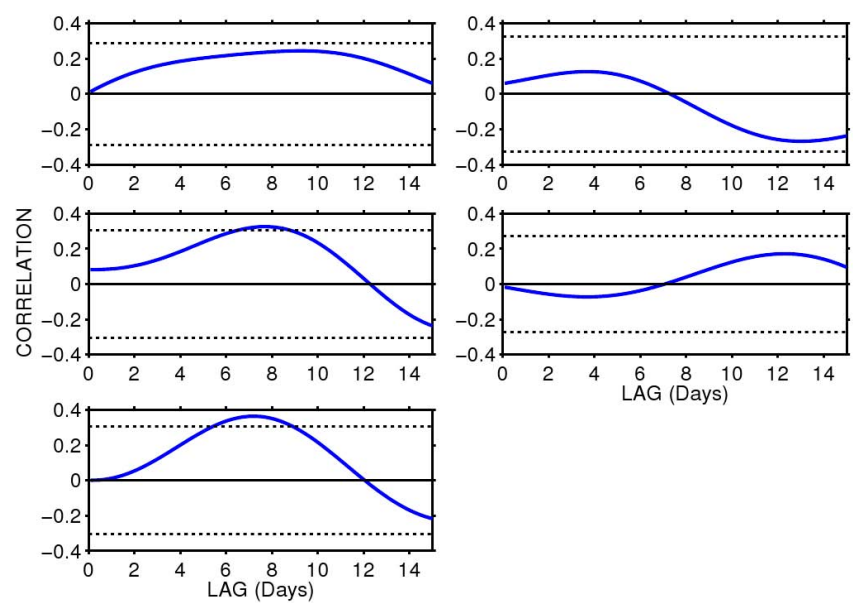

Fig. 17. Correlations (with lags applied to the UFKW zonal wind amplitude) between E1 amplitudes of oscillations with period 2.54.0 days in the tropospheric convective heating and in the amplitude of UFKW in the MLT, for five integrated years of the Kyushu-GCM. The dashed lines on the figures indicate the $95 \%$ confidence limits.

An analysis of Kyushu-GCM data was carried out to investigate the correlation and lag between UFKW amplitudes in the MLT and E1 amplitudes of similar period in tropospheric convective heating. In the latter case, E1 amplitudes with periods in the range $2.5-4.0$ days were considered. The results of this analysis are presented in Fig. 17.

The figure shows correlation as a function of lag for five integrated years of model output. Also indicated on each figure is the $95 \%$ confidence limit. Two of the five years show correlations of about 0.3 which exceeds the $95 \%$ confidence limits. These occur at lags of $\sim 7-8$ days, indicating that UFKW amplitudes maximise $\sim 7-8$ days after large amplitude E1 signals of similar period in tropospheric convective heating. However, we should note that in three of the years there was no significant correlation evident, suggesting that the connection between convective heating events and UFKW in the MLT of the Kyushu-GCM is not a simple oneto-one relationship.

We also investigated the connection between tropospheric heating and UFKW observed in the MLT using TRMM precipitation data. The precipitation data, used as a proxy for convective heating, was obtained from the TRMM "MultiSatellite Precipitation Analysis" 3B42 dataset. This provides three-hourly averages of the precipitation rate $\left(\mathrm{mm} \mathrm{h}^{-1}\right)$ for the latitude range $50^{\circ} \mathrm{N}-50^{\circ} \mathrm{S}$, longitudes $180^{\circ} \mathrm{W}-180^{\circ} \mathrm{E}$, on a grid with a resolution of $0.25 \times 0.25^{\circ}$. The data product is derived by calibrating the datasets of GMS, GOES-E, GOES-W, Meteosat-7, Meteosat-5 and NOAA-12 with data from TRMM's (Tropical Rainfall Measurement Mission) microwave imager (TMI) and visible and infra-red scanner (VIRS) instruments. TRMM-3B42 is available for all years considered here.
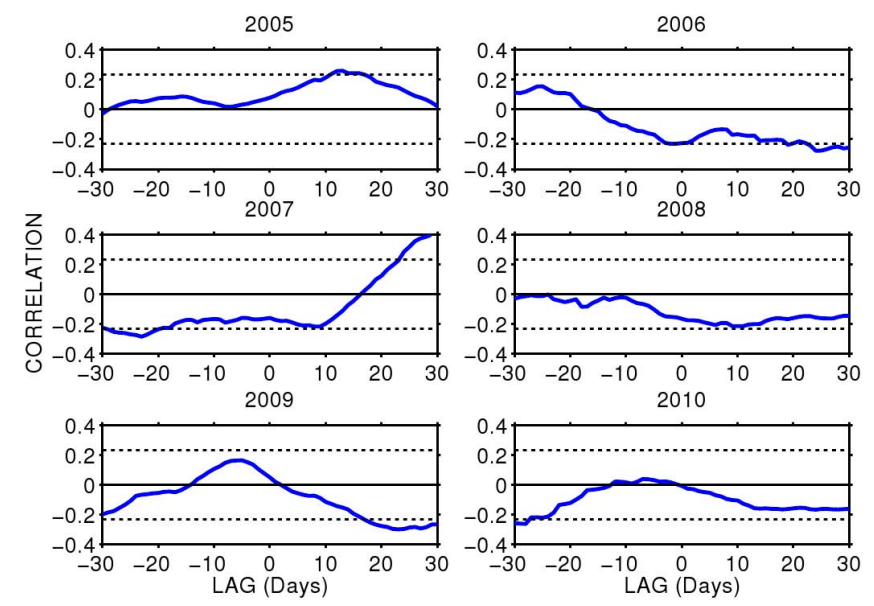

Fig. 18. Correlations (with time lags applied to the UFKW in the MLT) between E1 waves of period 2.5-4.5 days in the Aura analysis at a height of $97 \mathrm{~km}$ and similar oscillations in the TRMM analysis, from 2005 (top left) to 2010 (bottom right). The dashed lines on the figures indicate the $95 \%$ confidence limits.

The least squares fit method of Wu et al. (1995) was applied in a similar manner to that of the Aura MLS analysis to measure the amplitudes of E1 oscillations of period 2.54.5 days in the TRMM data that might be expected to excite E1 UFKW. Time series were produced of both the Aura E1 UFKW amplitudes in the mesosphere and the TRMM E1 spectral component.

Correlations were calculated between the two time series for each year using lags of between -30 and +30 days (such that a negative lag of, for example, -30 days represents the TRMM precipitations being correlated with the Aura results of 30 days earlier, a lag of 0 days represents the two time series being correlated at equal times, and a lag of +20 days represents the TRMM precipitations being correlated with the Aura results of 20 days later). The results of this analysis are presented for years 2005-2010 in Fig. 18.

From Fig. 18 it can be seen that the correlations vary greatly from year to year. Considering the results for 2005, the correlation maximises at a lag of approximately 10-15 days suggesting that UFKW manifest in the mesosphere 1015 days after E1 signatures of period 2.5-4.5 days occur in the tropospheric convective heating. This is in reasonable agreement with theoretical predictions that a UFKW with 4 day period should take about 10 days to reach a height of $100 \mathrm{~km}$. However, in the other years considered, this behaviour is not repeated, and significant correlations maximising at lags ranging from less than -20 to more than +20 occur and the correlations can be either positive or negative. Further, we examined the correlations at much greater lags than those shown in the figure, and found that significant correlations, either positive or negative, could also occur at these larger lags. A correlation analysis for the whole period 20052010 gave correlations in the range -0.01 to -0.07 for each of the lags but these values were not significant. 

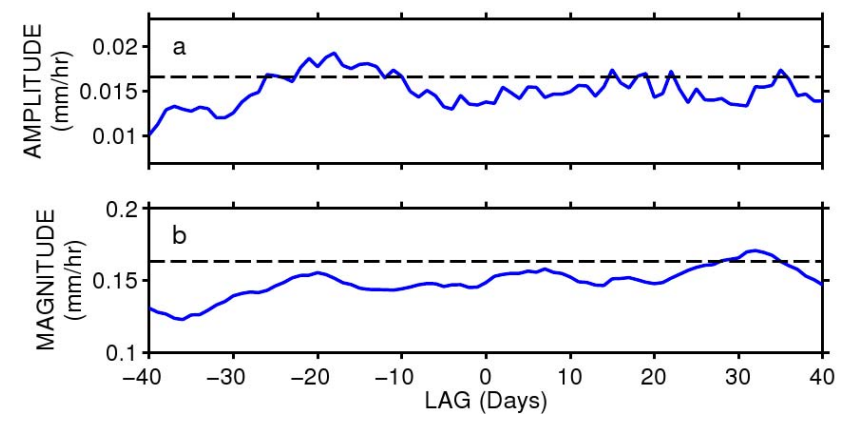

Fig. 19. (a) The average amplitude of E1 oscillations in the TRMM precipitation data at the same periods and times (with various lags added) at which UFKW are present in the Aura MLS data. (b) The average zonal-mean magnitude of precipitation rate in the TRMM data before (positive lag), during (zero lag) and after (negative lag) the times at which UFKW are present in the Aura MLS data. The dotted lines represent the average over all times, not just the times either side of the large-amplitude mesospheric UFKW events.

These results suggest that there is no significant tendency for mesospheric UFKW bursts to occur following peaks in the E1 signal in the tropospheric convective heating. However, due to the intermittent nature of UFKW, these correlations will include extended intervals when the spectra of the two datasets at the frequencies of interest contain only noise. This may explain the relatively low correlations between the Aura and TRMM datasets.

To try and address this problem, an analysis was applied which considered only the times of the 16 largest-amplitude UFKW events. The amplitudes of the E1 signatures in the TRMM precipitation data at the times and periods of these events were averaged. This was repeated with each of the lags applied. The convention of positive lag signifying that the mesospheric UFKW take place after the precipitation activity was retained. If mesospheric UFKW amplitudes peaked ten days after a large amplitude TRMM E1 signal, we might then expect to see the TRMM mean E1 amplitudes maximising at a lag of +10 days. These TRMM E1 average amplitudes as a function of lag are presented in Fig. 19a. A similar analysis was performed in which the total magnitude of the rainfall (rather than the amplitude of the E1 oscillations) was averaged around the full longitudinal circle for the times of the large-amplitude UFKW events, with lags applied. This analysis would identify a tendency for largeamplitude precipitation events to precede large-amplitude UFKW events in the MLT, as might be expected if the magnitude of precipitation was exciting UFKW. This result is presented in Fig. 19b. Note that positive lags correspond to a situation in which a high-magnitude precipitation event precedes UFKW in the MLT.

Figure 19a shows a small peak in the TRMM precipitation E1 amplitudes occurring approximately 10-20 days prior to the large amplitude UFKW events in the mesosphere (i.e. the broad peak on the right-hand side of the figure). This might suggest that the mesospheric UFKW tend to reach largest amplitudes 10-20 days after a large amplitude E1 2.5-4.5 day spectral component of large amplitude in precipitation (i.e. latent heat release). However, we note that there is a larger peak on the left-hand side of the figure occurring at a lag of about -20 days, which would indicate mesospheric UFKW amplitudes maximising before the peak in tropospheric latent heat release. We regularly observe peaks occuring at negative lags. We therefore conclude that small peaks at positive lags do not necessarily indicate a simple connection in which a large-amplitude E1 precipitation event leads to a large-amplitude UFKW signature in the mesosphere.

Figure $19 \mathrm{~b}$ shows that the magnitude of precipitation rate is similar before, during and after large-amplitude UFKW events in the mesosphere. These results, and the observation that the amplitudes of the E1 signatures and the zonalmean magnitudes of the rainfall at times either side of largeamplitude UFKW events are not above the long-term average, further suggest that there is not a simple relationship between the occurrence of large-amplitude mesospheric UFKW and the magnitude or E1 component of latent heat release.

\subsection{Intraseasonal oscillations}

It has been shown that there is a semiannual oscillation in the UFKW amplitudes of the radar winds and satellite temperatures. To investigate the presence of variability on shorter intraseasonal timescales, spectra were calculated for the entire datasets of radar winds, UFKW amplitudes in temperature and wind, zonal wind accelerations and TRMM rainfall rates. Figure 20 presents results of this analysis for specific heights. The Aura MLS UFKW spectrum has been cut off at the Nyquist limit of 20 days.

Large peaks are apparent at periods corresponding to the semiannual oscillation in many of the figures. However, in addition to these, peaks exceeding the $99 \%$ confidence limit are evident in all the spectra at periods of 25-60 days, corresponding to ISOs. In particular, many of the spectra show peaks at periods near 27, 37, 45 and 61 days; these periods are indicated on the figures by red, green, yellow and purple circles respectively. This result may indicate that regular episodes of increased UFKW amplitude result in regular episodes of increased zonal-wind acceleration, which in turn impose a periodicity at similar periods on the zonal winds themselves. Note that ISO amplitudes in the mean zonal wind in this period range reach up to about $5 \mathrm{~m} \mathrm{~s}^{-1}$ at the height shown $(\sim 87 \mathrm{~km})$, however they reached nearly $10 \mathrm{~m} \mathrm{~s}^{-1}$ in the lowest height gate $(\sim 81 \mathrm{~km})$. 


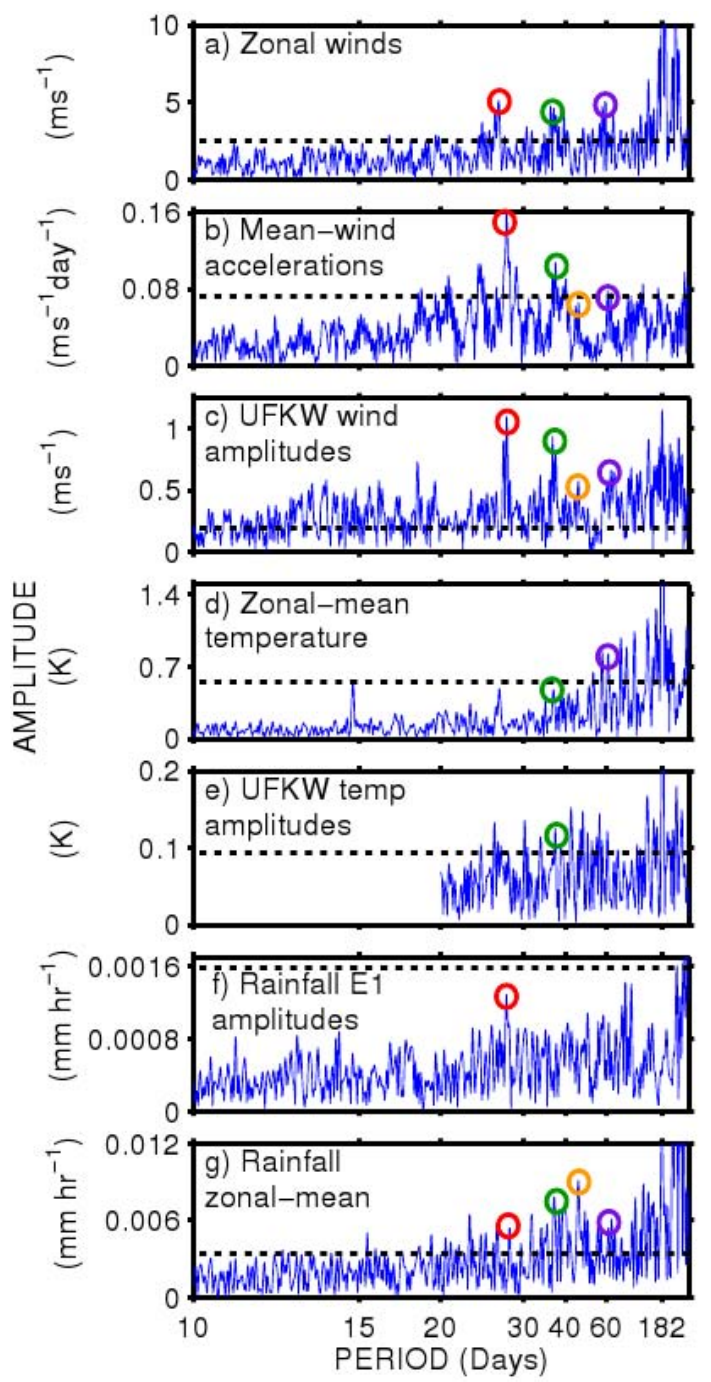

Fig. 20. Spectra of (a) zonal mean wind at a height of $87 \mathrm{~km}$, (b) mean-flow accelerations from UFKW derived from meteor radar zonal winds bandpassed in the 2.5-4.5 day range at a height of $83 \mathrm{~km}$, (c) UFKW wind amplitudes at a height of $81 \mathrm{~km}$, (d) zonalmean temperature derived from Aura MLS observations, (e) UFKW temperature amplitudes at a height of $96 \mathrm{~km}$, (f) E1 2.5-4.5 day signatures in the TRMM rainfall rate and (g) zonal-mean rainfall rate magnitudes. A ten day window was used for the UFKW amplitudes in the MLS temperatures so (e) has been cut off at the Nyquist limit. The dashed horizontal lines represent the $95 \%$ confidence limits. Different colour circles are used to identify frequencies of interest in successive plots.

\section{Discussion}

UFKW are observed to occur intermittently throughout the datasets in bursts lasting a few cycles, after which their amplitudes decrease again. UFKW Amplitudes in the zonal wind are seen to regularly exceed $15 \mathrm{~m} \mathrm{~s}^{-1}$ and occasionally reach $40 \mathrm{~m} \mathrm{~s}^{-1}$. This is comparable with the $25 \mathrm{~m} \mathrm{~s}^{-1}$ peak amplitudes of UFKW reported by Kovalam et al. (1999) using MF radars at Pontianak $\left(0^{\circ} \mathrm{N}, 109^{\circ} \mathrm{E}\right)$ and Christmas Island $\left(2^{\circ} \mathrm{N}, 157^{\circ} \mathrm{W}\right)$, and peak amplitudes exceeding $30 \mathrm{~m} \mathrm{~s}^{-1}$ reported by Riggin et al. (1997) using a meteor radar at Jakarta $\left(6^{\circ} \mathrm{S}, 107^{\circ} \mathrm{E}\right)$ and an MF radar on Christmas Island. Our observed amplitudes are also very similar to the amplitudes of 5-40 $\mathrm{m} \mathrm{s}^{-1}$ reported for UFKW in the Kyushu-GCM (Chen and Miyahara, 2011).

In the Aura MLS temperature data, UFKW generally have amplitudes of around $3 \mathrm{~K}$, although some individual events reached amplitudes of $6 \mathrm{~K}$. This is in very good agreement with the values reported in TIMED/SABER data by Forbes et al. (2009).

UFKW are usually evident in the radar winds at the same times as they are observed in the satellite data. There is good agreement between the wave frequencies simultaneously observed by the two datasets.

Wave amplitudes in both the radar and MLS data increase with height. Considering the 16 large-amplitude events used in Fig. 9, the amplitude grows approximately linearly with height, and is thus less than the $e^{\frac{z}{2 h}}$ rate which would correspond to non-dissipative wave propagation. This indicates that there is some dissipation.

The seasonal variability of UFKW in both the wind and temperature data reveals a semiannual variation with largest amplitudes in February and July/August (a smaller secondary maximum is seen in the radar data in November). For comparison, Vincent (1993) observed an approximately similar semiannual pattern with maximum UFKW amplitudes in January-February and August/September over Christmas Island. Similarly, Yoshida et al. (1999) also observed a semiannual variability in UFKW amplitudes over Jakarta.

Our results suggest that UFKW amplitudes and variances in the MLT vary as a function of longitude and reach largest values over Indonesia. Here we should note that Riggin et al. (1997) found higher amplitudes of UFKW over Jakarta in Indonesia $\left(6.4^{\circ} \mathrm{S}, 106^{\circ} \mathrm{E}\right)$ than over Christmas Island in the central Pacific $\left(1.9^{\circ} \mathrm{N}, 157.3^{\circ} \mathrm{W}\right)$, despite Jakarta being further from the equator and thus further from the equatorial peak in amplitudes. They suggested that the larger amplitudes over Jakarta may be attributed to the Indonesian region's vigourous convection, making it a site for strong UFKW excitation.

Kovalam et al. (1999) also reported different amplitudes at different longitudes, but in a study using two similar MF radars, with larger amplitudes over Pontianak $\left(0^{\circ} \mathrm{N}, 109^{\circ} \mathrm{E}\right)$ than over Christmas Island by a factor of 1.4. They also suggested that the longitudinal variability was due to source effects. This suggests that the longitudinal variability evident in Figs. 6 and 11 is of geophysical origin.

Our global observations confirm the earlier suggestions that UFKW amplitudes maximise over Indonesia. This evidence provides strong support for the suggestion of Riggin et al. (1997) that the region of high convective activity over Indonesia is a vigorous source of equatorial waves. However, we notice that there is no apparent secondary peak in 
UFKW variances over the convective region of South America. However, our observation that this longitudinal peak in variance is not evident at latitudes away from the equator (where the inertial period limit falls out of the 2.5-4.5 day range) may still suggest that waves other than UFKW are contributing to this maximum.

The variation of amplitude with latitude evident in Fig. 9 is approximately gaussian and maximises over the equator with an e-folding half-width of $\sim 27^{\circ}$ of latitude. Following the work of Holton and Lindzen (1968) the e-folding halfwidth of Kelvin waves can be shown to be

$L_{y} \simeq \sqrt{\frac{2 \omega}{\beta k}}$

where for the beta-plane centred over the equator $\beta=\frac{2 \Omega}{r_{\mathrm{E}}}$, for the Earth's rotation rate $\Omega$ (in rad s${ }^{-1}$ ) and Earth's radius $r_{\mathrm{E}}$. UFKW of zonal wavenumber 1 and period of 3.5 days (the average period of the 16 large-amplitude events included in Fig. 9) have zonal phase speeds of $\frac{\omega}{k} \simeq 130 \mathrm{~m} \mathrm{~s}^{-1}$. This corresponds to a predicted half-width of $L_{y} \simeq 3400 \mathrm{~km}$, or $30.5^{\circ}$ of latitude. This is remarkably close to our observed result of $\sim 27^{\circ}$ of latitude and further confirms our inference that the analysis is detecting UFKW.

The average vertical wavelength of Table $1, \lambda_{z}=44 \pm$ $2 \mathrm{~km}$, is consistent with the average $\lambda_{z}$ values of $41 \mathrm{~km}$ found by Salby et al. (1984), and $43 \mathrm{~km}$ found by both Sridharan et al. (2002) and Lima et al. (2008), but considerably shorter than the values of 87 and $116 \mathrm{~km}$ reported by Riggin et al. (1997) and values between 53 and $88 \mathrm{~km}$ observed by Kovalam et al. (1999). A wave of wavenumber 1 travelling around the equator would have a horizontal wavelength approximately equal to the circumference of the equator, i.e. $\lambda_{x}=40700 \mathrm{~km}$. Using the Kelvin wave dispersion relation,

$\lambda_{z}=T_{B}\left[\frac{\lambda_{x}}{\tau}-\bar{u}\right]$,

and using values of $T_{B} \simeq 300 \mathrm{~s}$ for the MLT region BruntVäisälä period and $\bar{u}=0 \mathrm{~m} \mathrm{~s}^{-1}$ as an approximation for the mean wind (Forbes et al., 2009) we obtain vertical wavelengths ranging from 31.4 to $56.5 \mathrm{~km}$ for UFKW with periods $\tau=2.5-4.5$ days. These numbers are in excellent agreement with the observations presented in Table 1.

As UFKW dissipate, they deposit their eastward momentum into the mean flow, creating an eastward acceleration. The accelerations measured here (Figs. 15 and 16) are seen to be almost always eastward. The range of monthly-mean values at heights near $95 \mathrm{~km}$ of $\sim 0.2-0.9 \mathrm{~m} \mathrm{~s}^{-1} \mathrm{day}^{-1}$, is similar to that obtained from radar measurements at Pontianak (Kovalam et al., 1999). The average monthly mean value of $0.44 \mathrm{~m} \mathrm{~s}^{-1}$ day $^{-1}$ is slightly greater than that obtained at Christmas Island of $0.32 \mathrm{~m} \mathrm{~s}^{-1} \mathrm{day}^{-1}$, but less than that obtained at Jakarta of $0.67 \mathrm{~m} \mathrm{~s}^{-1}$ day $^{-1}$ (Riggin et al., 1997). Peak accelerations associated with large events can reach up to $\sim 4 \mathrm{~m} \mathrm{~s}^{-1}$ day $^{-1}$. This suggests that UFKW make a small contribution to the equatorial MLT region when compared to, for example, the contribution of gravity waves at midlatitudes (e.g. Norton and Thuburn, 1999).

In Sect. 3.4 we considered correlations between tropospheric rainfall parameters and UFKW amplitudes in the MLT. Although in 2005 there was a peak in the correlation at lags of 10-20 days that is significant at the $95 \%$ level, in other years the correlation at these lags was actually weakly negative. These low correlation values might be due to the episodic nature of the UFKW, as the time series being correlated will include long intervals of time during which there is little to no activity, and so noise would reduce the correlations. However, we might still have expected that the magnitude or the average amplitude of E1 signatures in the rainfall would be larger than average before the occurrence of a burst of mesospheric UFKW. However, this was not observed. These observations suggest that there is no simple relationship between these rainfall parameters and the occurrence of large-amplitude UFKW in the MLT. Nevertheless, the results presented in Fig. 20 suggest a link between ISOs in the rainfall and ISOs in the mesospheric UFKW amplitudes.

ISOs were found in the two rainfall parameters considered, in the UFKW amplitudes and mean-flow accelerations, background zonal winds and zonal-mean temperatures with clusters of spectral peaks at periods in the 30-60 day range associated with the Madden-Julian oscillation and the 20-25 day range associated with the oscillation reported by Hartmann et al. (1992) (Fig. 20). Similar observations of ISOs in UFKW temperature amplitudes and zonal-mean temperature have been reported by Forbes et al. (2009) in TIMED/SABER data. Our results suggest that ISOs in zonal-mean rainfall (a proxy for tropospheric convective heating) result in modulation of UFKW amplitudes in the MLT at similar periods. This in turn modulates the mean-wind accelerations caused by the dissipation of those UFKW. It is interesting to note that the zonal winds also show periodicities that match well with those of the mean-wind accelerations, from which one might infer that these oscillations in the mean wind were being driven by the momentum deposition from UFKW. However, we should note that ISOs are also know to exist in gravity-wave and diurnal-tidal amplitudes (Miyoshi and Fujiwara, 2006; Eckermann et al., 1997) which can also contribute to ISOs in the zonal winds. The relative role of UFKW, gravity waves and tides in exciting mean wind ISOs in the MLT thus remains to be determined.

\section{Conclusions}

Winds from the Ascension Island meteor radar $\left(8^{\circ} \mathrm{S}, 14^{\circ} \mathrm{W}\right)$ and temperatures recorded simultaneously by the Aura MLS instrument have been analysed to characterise ultra-fast Kelvin waves of period 2.5-4.5 days at equatorial latitudes and at heights of up to $\sim 100 \mathrm{~km}$. These have been compared 
with observations made from the Kyushu-GCM and in the TRMM rainfall data. Our conclusions are as follows:

1. Clear but intermittent UFKW are observed with zonal wind amplitudes reaching up to $40 \mathrm{~m} \mathrm{~s}^{-1}$ and temperature amplitudes of up to $6 \mathrm{~K}$. The average vertical wavelength is $\lambda_{z}=44 \pm 2 \mathrm{~km}$. The variation of UFKW amplitude with latitude is observed to be approximately gaussian with an e-folding half-width of $27^{\circ}$ of latitude.

2. There is good agreement of UFKW observations in the radar zonal winds and in the Aura MLS temperatures, with UFKW found simultaneously at the same frequencies in both datasets.

3. Amplitudes do not grow at the exponential free growth rate with height which means that the waves dissipate, depositing eastward momentum into the mean flow. Monthly mean acceleration values are found to be $0.2-$ $0.9 \mathrm{~m} \mathrm{~s}^{-1} \mathrm{day}^{-1}$ at heights near $95 \mathrm{~km}$.

4. A semiannual variation in wave amplitude is evident in both datasets with largest amplitudes in February and July/August.

5. A longitudinal variability is found in the variance of temperature perturbations associated with these waves with largest values over Indonesia and Africa. This is attributed to the strong tropospheric convection of these regions. The absence of a peak in activity over South America is unexplained.

6. No clear link is found between the occurrence of largeamplitude mesospheric UFKW and E1 signatures in rainfall or zonal-mean magnitude of rainfall.

7. ISOs with periods between $\sim 25-60$ days are observed in the long-term spectra for the mean zonal winds, the zonal-mean temperatures, the UFKW amplitudes and associated mean-flow accelerations, and in the rainfall magnitudes. This supports the suggestion that the tropospheric Madden-Julian oscillation and the 20-25 day oscillation of Hartmann et al. (1992) modulate the intensity of UFKW, which then propagate upwards and contribute to similar periodicities in the background winds by wave-mean flow interactions. However, the relative role of UFKW, gravity-waves and tides in driving ISOs in the zonal winds has yet to be determined.

Edited by: A. J. G. Baumgaertner

\section{References}

Canziani, P. O., Holton, J. R., Fishbein, E., Froidevaux, L., and Waters, J. W.: Equatorial Kelvin waves - a UARS MLS view, J. Atmos. Sci., 51, 3053-3076, doi:10.1175/15200469(1994)051<3053:EKWAUM>2.0.CO;2, 1994.
Chang, L. C., Palo, S. E., Liu, H. L., Fang, T. W., and Lin, C. S.: Response of the thermosphere and ionosphere to an ultra fast Kelvin wave, J. Geophys. Res.-Space, 115, A00G04, doi:10.1029/2010JA015453, 2010.

Chen, Y.-W. and Miyahara, S.: Analysis of fast and ultra-fast Kelvin waves simulated by the Kyushu-GCM, J. Atmos. Sol.-Terr. Phy., submitted, 2011.

Dunkerton, T. J.: Role of the Kelvin wave in the westerly phase of the semiannual zonal wind oscillation, J. Atmos. Sci., 36, 32-41, doi:10.1175/1520-0469(1979)036<0032:OTROTK > 2.0.CO;2, 1979.

Dunkerton, T. J.: The role of gravity waves in the quasibiennial oscillation, J. Geophys. Res.-Atmos., 102, 2605326076, doi:10.1029/96JD02999, 1997.

Eckermann, S. D. and Vincent, R. A.: 1st observations of intraseasonal oscillations in the equatorial mesosphere and lower thermosphere, Geophys. Res. Lett., 21, 265-268, doi:10.1029/93GL02835, 1994.

Eckermann, S. D., Rajopadhyaya, D. K., and Vincent, R. A.: Intraseasonal wind variability in the equatorial mesosphere and lower thermosphere: Long-term observations from the central Pacific, J. Atmos. Sol.-Terr. Phy., 59, 603-627, doi:10.1016/S1364-6826(96)00143-5, 1997.

Forbes, J. M.: Wave coupling between the lower and upper atmosphere: case study of an ultra-fast Kelvin Wave, J. Atmos. Sol.Terr. Phy., 62, 1603-1621, doi:10.1016/S1364-6826(00)001152, 2000.

Forbes, J. M., Zhang, X. L., Palo, S. E., Russell, J., Mertens, C. J., and Mlynczak, M.: Kelvin waves in stratosphere, mesosphere and lower thermosphere temperatures as observed by TIMED/SABER during 2002-2006, Earth Planets Space, 61, 447-453, 2009.

Hartmann, D. L., Michelsen, M. L., and Klein, S. A.: Seasonalvariations of tropical intraseasonal oscillations - a 20-25 day oscillation in the western Pacific, J. Atmos. Sci., 49, 1277-1289, doi:10.1175/1520-0469(1992)049<1277:SVOTIO > 2.0.CO;2, 1992.

Hirota, I.: Equatorial waves in upper stratosphere and mesosphere in relation to semiannual oscillation of zonal wind, J. Atmos. Sci., 35, 714-722, doi:10.1175/15200469(1978)035<0714:EWITUS > 2.0.CO;2, 1978.

Hitchman, M. H. and Leovy, C. B.: Estimation of the Kelvin wave contribution to the Semiannual Oscillation, J. Atmos. Sci., 45, 1462-1475, doi:10.1175/15200469(1988)045<1462:EOTKWC>2.0.CO;2, 1988.

Holton, J. R.: On the frequency distribution of atmospheric Kelvin waves, J. Atmos. Sci., 30, 499-501, doi:10.1175/15200469(1973)030<0499:OTFDOA > 2.0.CO;2, 1973.

Holton, J. R.: An introduction to dynamic meteorology second edition, Academic Press Inc., New York, 1979.

Holton, J. R. and Lindzen, R. S.: A note on Kelvin waves in the atmosphere, Mon. Weather Rev., 96, 385-386, doi:10.1175/15200493(1968)096<0385:ANOKWI>2.0.CO;2, 1968.

Holton, J. R. and Lindzen, R. S.: Updated theory for quasi-biennial cycle of tropical stratosphere, J. Atmos. Sci., 29, 1076-1080, doi:10.1175/1520-0469(1972)029<1076:AUTFTQ>2.0.CO;2, 1972.

Kawatani, Y., Sato, K., Dunkerton, T. J., Watanabe, S., Miyahara, S., and Takahashi, M.: The roles of equatorial trapped waves 
and internal inertia-gravity waves in driving the Quasi-Biennial Oscillation. Part I: Zonal mean wave forcing, J. Atmos. Sci., 67, 963-980, doi:10.1175/2009JAS3222.1, 2010.

Kovalam, S., Vincent, R. A., Reid, I. M., Tsuda, T., Nakamura, T., Ohnishi, K., Nuryanto, A., and Wiryosumarto, H.: Longitudinal variations in planetary wave activity in the equatorial mesosphere, Earth Planets Space, 51, 665-674, 1999.

Lieberman, R. S.: Intraseasonal variability of high-resolution Doppler imager winds in the equatorial mesosphere and lower thermosphere, J. Geophys. Res.-Atmos., 103, 11221-11228, doi:10.1029/98JD00532, 1998.

Lieberman, R. S. and Riggin, D. M.: High resolution Doppler imager observations of Kelvin waves in the equatorial mesosphere and lower thermosphere, J. Geophys. Res.-Atmos., 102, $26117-$ 26130, doi:10.1029/96JD02902, 1997.

Lima, L. M., Alves, E. D., Medeiros, A. F., Buriti, R. A., Batista, P. P., Clemesha, B. R., and Takahashi, H.: 3-4 day Kelvin waves observed in the MLT region at 7.4 degrees S, Brazil, Geofisica Int., 47, 153-160, 2008.

Lindzen, R. D.: Planetary waves on beta-planes, Mon. Weather Rev., 95, 441-451, doi:10.1175/15200493(1967)095<0441:PWOBP>2.3.CO;2, 1967.

Madden, R. A. and Julian, P. R.: Detection of a 40-50 day oscillation in zonal wind in tropical Pacific, J. Atmos. Sci., 28, 702-708, doi:10.1175/1520-0469(1971)028<0702:DOADOI > 2.0.CO;2, 1971.

Madden, R. A. and Julian, P. R.: Observations of the 40-50 day tropical oscillation - a review, Mon. Weather Rev., 122, 814-837, doi:10.1175/1520-0493(1994)122<0814:OOTDTO>2.0.CO;2, 1994.

Miyoshi, Y. and Fujiwara, H.: Excitation mechanism of intraseasonal oscillation in the equatorial mesosphere and lower thermosphere, J. Geophys. Res.-Atmos., 111, D14108, doi:10.1029/2005JD006993, 2006.

Norton, W. A. and Thuburn, J.: Sensitivity of mesospheric mean flow, planetary waves, and tides to strength of gravity wave drag, J. Geophys. Res.-Atmos., 104, 30897-30911, doi:10.1029/1999JD900961, 1999.

Pancheva, D., Mitchell, N. J., and Younger, P. T.: Meteor radar observations of atmospheric waves in the equatorial mesosphere/lower thermosphere over Ascension Island, Ann. Geophys., 22, 387-404, doi:10.5194/angeo-22-387-2004, 2004.

Rao, R. K., Gurubaran, S., Sathiskumar, S., Sridharan, S., Nakamura, T., Tsuda, T., Takahashi, H., Batista, P. P., Clemesha, B. R., Buriti, R. A., Pancheva, D. V., and Mitchell, N. J.: Longitudinal variability in intraseasonal oscillation in the tropical mesosphere and lower thermosphere region, J. Geophys. Res.-Atmos., 114, D19110, doi:10.1029/2009JD011811, 2009.

Riggin, D. M., Fritts, D. C., Tsuda, T., Nakamura, T., and Vincent, R. A.: Radar observations of a 3-day Kelvin wave in the equatorial mesosphere, J. Geophys. Res.-Atmos., 102, 26141-26157, doi:10.1029/96JD04011, 1997.
Salby, M. L. and Garcia, R. R.: Transient-response to localized episodic heating in the tropics. 1. Excitation and short-time nearfield behaviour, J. Atmos. Sci., 44, 458-498, doi:10.1175/15200469(1987)044<0458:TRTLEH>2.0.CO;2, 1987.

Salby, M. L., Hartmann, D. L., Bailey, P. L., and Gille, J. C.: Evidence for equatorial kelvin modes in NIMBUS7 LIMS, J. Atmos. Sci., 41, 220-235, doi:10.1175/15200469(1984)041<0220:EFEKMI>2.0.CO;2, 1984.

Schwartz, M. J., Lambert, A., Manney, G. L., Read, W. G., Livesey, N. J., Froidevaux, L., Ao, C. O., Bernath, P. F., Boone, C. D., Cofield, R. E., Daffer, W. H., Drouin, B. J., Fetzer, E. J., Fuller, R. A., Jarnot, R. F., Jiang, J. H., Jiang, Y. B., Knosp, B. W., Kruger, K., Li, J. L. F., Mlynkzac, M. G., Pawson, S., Russell, J. M., Santee, M. L., Snyder, W. V., Stek, P. C., Thurstans, R. P., Tompkins, A. M., Wagner, P. A., Walker, K. A., Waters, J. W., and $\mathrm{Wu}, \mathrm{D}$. L.: Validation of the aura microwave limb sounder temperature and geopotential height measurements, J. Geophys. Res.-Atmos., 113, D15S11, doi:10.1029/2007JD008783, 2008.

Sridharan, S., Gurubaran, S., and Rajaram, R.: Radar observations of the 3.5-day ultra-fast Kelvin wave in the low-latitude mesopause region, J. Atmos. Sol.-Terr. Phy., 64, 1241-1250, doi:10.1016/S1364-6826(02)00072-X, 2002.

Takahashi, M. and Boville, B. A.: A 3-dimensional simulation of the equatorial quasi-biennial oscillation, J. Atmos. Sci., 49, 1020-1035, doi:10.1175/15200469(1992)049<1020:ATDSOT>2.0.CO;2, 1992.

Takahashi, H., Wrasse, C. M., Fechine, J., Pancheva, D., Abdu, M. A., Batista, I. S., Lima, L. M., Batista, P. P., Clemensha, B. R., Schuch, N. J., Shiokawa, K., Gobbi, D., Mlynkzac, M. G., and Russell, J. M.: Signatures of ultra fast Kelvin waves in the equatorial middle atmosphere and ionosphere, Geophys. Res. Lett., 34, L11108, doi:10.1029/2007GL029612, 2007.

Vincent, R. A.: Long-period motions in the equatorial mesosphere, J. Atmos. Sol.-Terr. Phy., 55, 1067-1080, doi:10.1016/00219169(93)90098-J, 1993.

Wallace, J. M. and Kousky, V. E.: Observational evidence of Kelvin waves in tropical stratosphere, J. Atmos. Sci., 25, 900-907, doi:10.1175/1520-0469(1968)025<0900:OEOKWI>2.0.CO;2, 1968.

Wu, D. L., Hays, P. B., and Skinner, W. R.: A leastsquares method for spectral analysis of space-time series, J. Atmos. Sci., 52, 3501-3511, doi:10.1175/15200469(1995)052<3501:ALSMFS > 2.0.CO;2, 1995.

Yoshida, S., Tsuda, T., Shimizu, A., and Nakamura, T.: Seasonal variations of 3.0 similar to 3.8-day ultra-fast Kelvin waves observed with a meteor wind radar and radiosonde in Indonesia, Earth Planets Space, 51, 675-684, 1999.

Younger, P. T. and Mitchell, N. J.: Waves with period near 3 days in the equatorial mesosphere and lower thermosphere over Ascension Island, J. Atmos. Sol.-Terr. Phy., 68, 369-378, doi:10.1016/j.jastp.2005.05.008, 2006. 